\title{
Invasive Lobular Breast Carcinoma
}

National Cancer Institute

\section{Source}

National Cancer Institute. Invasive Lobular Breast Carcinoma. NCI Thesaurus. Code C7950.

An infiltrating lobular adenocarcinoma of the breast. The malignant cells lack cohesion and are arranged individually or in a linear manner (Indian files), or as narrow trabeculae within the stroma. The malignant cells are usually smaller than those of ductal carcinoma, are less pleomorphic, and have fewer mitotic figures. 